\title{
Print and electronic books and journals
}

\author{
Ganesalingam Narenthiran ${ }^{1,2,3} \cdot$ Frederick Boop ${ }^{3}$
}

Received: 20 March 2015 / Accepted: 30 March 2015 /Published online: 10 April 2015

(C) Springer-Verlag Berlin Heidelberg 2015

'A room without books is like a body without a soul'.

-Marcus Tullius Cicero

The other day, we noticed to our delight, on the bookshelf in the residents' office, Matson's 'Neurosurgery of infancy and childhood' and Plum and Posner's 'Diagnosis of stupor and coma', sitting alongside the latest edition of Youmans neurological surgery. We could not help but wonder what will become the fate of neurosurgery books in our Internet age; would it mirror that of vinyl records? Would tomorrow's neurosurgery residents know the joy of holding in their hands a newly minted textbook and be inspired, as most of us have? Would we even have bookshelves in the future? The publishing industry is going through a paradigm shift, transitioning its focus from the long-cherished books and printed journals to electronic textbooks and electronic journals.

It is said that the only constant in our world is change. Change inevitably has two sides. What are the advantages of electronic books and electronic journals? What might we loose with the demise of books?

While neurosurgery is relatively young, it undeniably has a rich culture forged by many multi-talented surgeons. It is no coincidence that the father of modern neurosurgery, Harvey

Ganesalingam Narenthiran

g_narenthiran@hotmail.com

1 Department of Neurosurgery, The Royal London Hospital, London E1 1BB, UK

2 Department of Neurological Surgery, University of Washington, Seattle, WA, USA

3 Department of Neurosurgery, St. Jude Children's Research Hospital, University of Tennessee Health Science Center, Memphis, TN, USA
Cushing, was, besides, a pioneering surgeon, a Pulitzer prizewinning author. He was also an assiduous book collector. It is said that books and authors had been an integral part of his life [1]. Cushing along with his friends and fellow bibliophiles, Arnold Klebs and John Fulton offered to donate their superb book collections to the Yale University, provided that the university builds a facility to house them. On the 3 October 1939, while lifting a weighty volume of Andreas Vesalius' anatomy text, Harvey Cushing had severe persistent chest pain for which he was hospitalized and, was diagnosed to have suffered a myocardial infarction. While he was in the hospital, he learnt that Yale University had accepted his proposal for the library. However, on the night of 7 October, he died in the hospital. The central medical library of Yale Medical School is now named the Harvey Cushing/John Hay Whitney Medical Library. Moreover, the book on Andreas Vesalius by Cushing saw publication posthumously in 1943.

The long and distinguished history of books as a source of transferring knowledge precedes antiquity. The earliestsurviving Babylonian clay tablets and Egyptian papyrus scrolls date back to the third millennium BC. However, it was in China where the first clay- and glue-based movable types were developed around $1040 \mathrm{AD}$ by Pi Shang. In the West, Johannes Gutenberg from Mainz developed the movable metal press in 1454, heralding a revolution in publishing. However, now, books are in retreat in the face of growing demand for often cheaper electronic books. The popularity of electronic books owes much to the advent of tablet computers.

The authors of this editorial are not against electronic academic media. There are enormous advantages to be had with them. They are cheaper to produce, easier to distribute and can be purchased and accessed at any time, provided you have secure Internet connection. A whole collection of books could be held in a tablet computer, an ultra-portable library! Tablet 
computers are easy on the arms compared to the heavy tomes. With sophisticated electronic readers, the literature could be zoomed, highlighted, marked and easily cross referenced allowing dissection of the material. Electronic books could have multi-media content and also could be cross referenced to resources on the Internet. They also allow personally made notes to be attached to electronic books and reprints. Moreover, the reprints could be saved along with the references in bibliography software. Furthermore, facilities are also being created to rent electronic books for a short period as well as lend them to friends and acquaintances.

So, why many of us bemoan the demise of books? Old habits die hard. Some of us like the physical intimacy of books. It brings the reader to the editors and the authors closer than any electronic media could. Some like the tactile romance of flicking the pages and seeing progress being made as one works through their way. For some, books have been companions and for others making of them. Cushing is said to have "cuddled old books and hugged them close" when there was death in the operating room or in his family [1].

How many of you have those cherished books that have been given as presents from family members, friends, colleagues or authors, scribbled with best wishes and lovingly signed? How many of you have gifted books as presents to your children, loved ones and colleagues? You cannot replicate this with electronic media.

While book collections could be left to the next generation of family members, bequeathed to local libraries or donated to institutions in developing countries, what would happen to electronic book collections after the collectors have passed away?

While, for publishing industry, electronic books might provide a larger margin of profit by cutting down on the merchants previously needed for distributing books, it is not without inherent problems such piracy. Piracy of books and journal reprints has been a problem for publishing industry. However, this is likely to get worse with the electronic books and journals.

Publishing a book is considered to be a service to society and contribution to scholarship, but it is also a matter prestige - a hard evidence of erudition, achievement and recognition. Would authors be tempted, if their toils would only be published in electronic format?

When one reads a book, it is easy to see the whole and able to dip in-and-out while still knowing the seam. It is not so easy to see the whole picture with electronic books. Moreover, when you read a printed journal, one tends to glance at the arresting front cover, browse to see who is the editor-in-chief and check to see who now makes up the editorial board. Additionally, we have seen walls of proud neurosurgeons, adorned with framed illustrations from their papers which have made the cover of the journal. You cannot so easily replicate this with electronic media.

When one held the four volumes of Youmans, one felt the scholarship, breath and depth of neurosurgery. Would an electronic version of Youmans in a tablet computer convey the majesty of the specialty? This brings us to the most important question whether electronic books and journals affect scholarship. Books are usually written for linear study. Ditmyer $\mathrm{MM}$ et al. [2] found that students studied using electronic books in a non-linear segmental fashion. They also found dental students preferred printed books to electronic books. If there was no economical or shelf-space constraints, the authors would also prefer printed books to electronic books.

While content is king, soul is stirred by beauty. The latter is abundantly evidenced from the popularity of Taj Mahal. For bibliophiles, printed books and journals combine content, beauty, history and touch of immortality.

We undertook a survey of neurosurgeons regarding their attitude to electronic and traditional academic books. The
Fig. 1 The response to the question: how should future textbooks be published? $(n=29)$

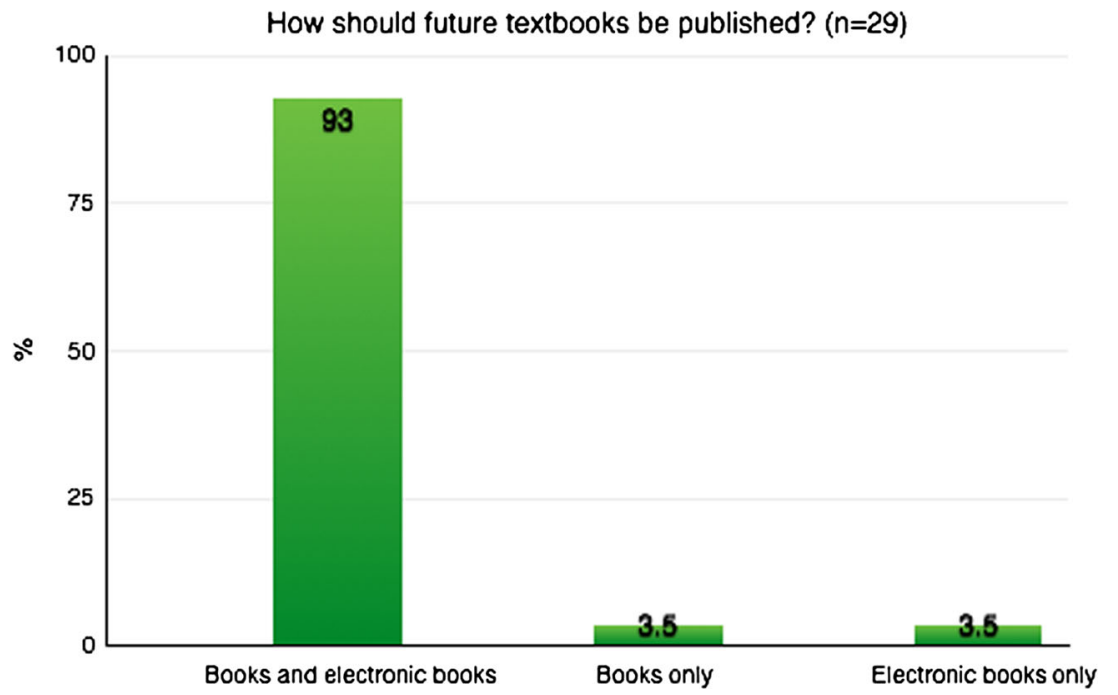


Fig. 2 The response to the question: if you have previously used electronic books, what type of textbook would your next purchase be?
If you have previously used electronic books, what type of textbook would your next purchase be?

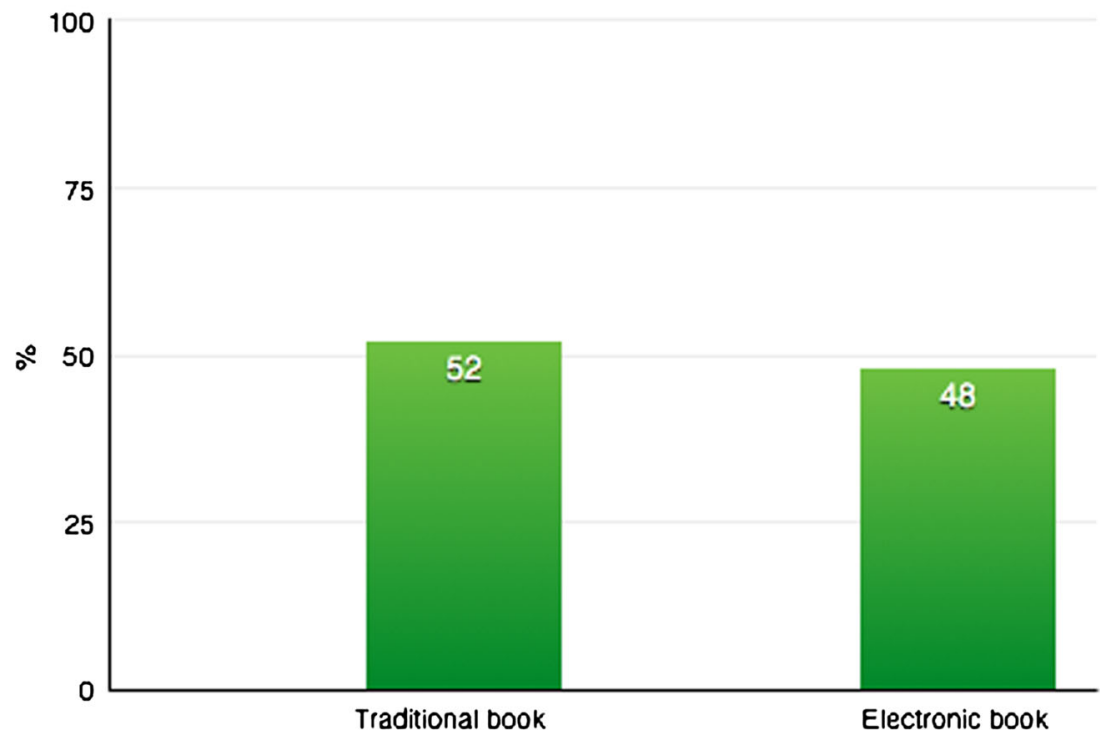

questionnaire was sent to the Neurosurgery Research ListServ $(n=675)$, and the survey was undertaken between 2 and 9 October 2014. The questionnaire [3] was an electronic form created with Google Forms ${ }^{\mathrm{TM}}$. The response rate $(n=29)$ was small to make firm conclusions. Nevertheless, the responses were informative.

Twenty-seven of the 29 (93\%) respondents reported that they would prefer textbooks be published in both paper-based and electronic book versions (Fig. 1). Forty-eight percent of the 29 respondents who had previously studied from electronic books reported that their next purchase of a textbook would be in electronic format; however, $52 \%$ reported that the next purchase would be a paper-based textbook (Fig. 2). Ninetythree percent of the respondents reported that, should they buy a gift, it would be a book rather than an electronic book (Fig. 3).

It would thus appear that while the traditional paper-based textbook has lost its monopoly, it is unlikely that it would disappear. Stephen Fry, a British commentator of contemporary culture, observed that "elevators have not done away with stairs; so with printed media and electronic media" - each has its place.

'My best friend is a person who will give me a book I have not read'.-Abraham Lincoln
Fig. 3 The response to the question: what type of textbook would you buy as a gift?
What type of textbook would you buy as a gift?

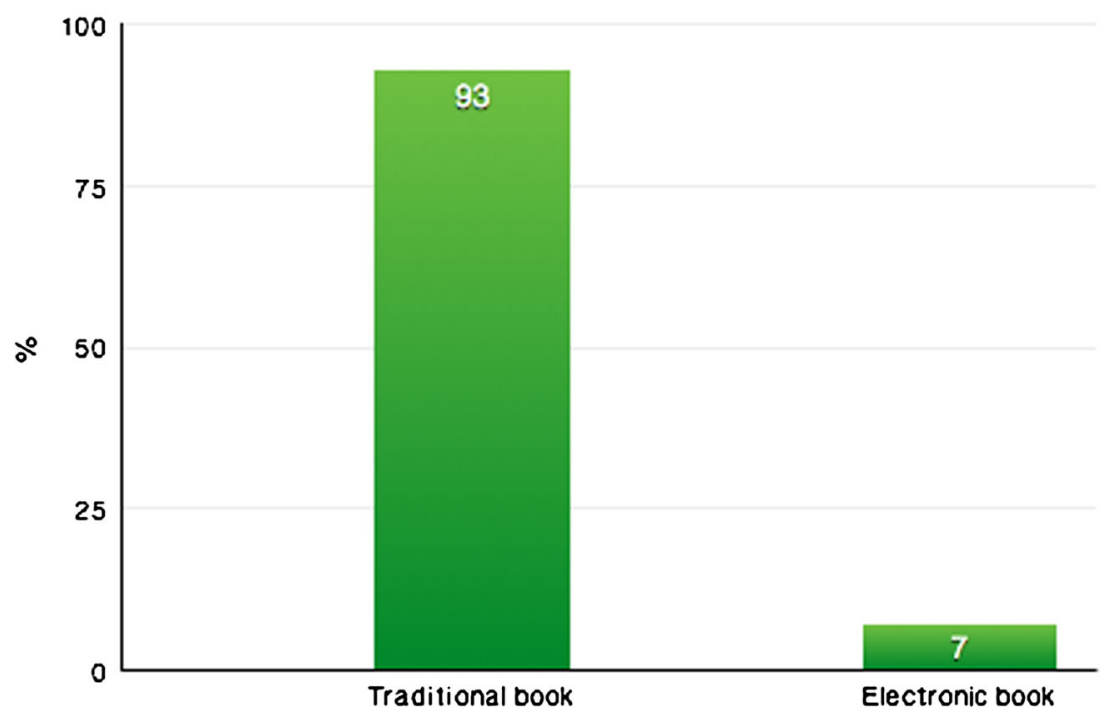




\section{References}

1. Bliss M (2005) Harvey Cushing: a life in surgery. Oxford University Press, Oxfors

2. Ditmyer MM, Dye J, Guirguis N, Jamison K, Moody M, Mobley CC, Davenport WD (2012) Electronic vs traditional textbook use: dental students' perceptions and study habits. J Dental Education 76: 728-738

3. Narenthiran G, Boop F (2014) Books or electronic books. Narenthiran, Ganesalingam. https://docs.google.com/forms/d/ 1t3UCsLQkHH8AQ9zZKDkYM6eBnPsMiySQEpaCN1UArgQ/ viewform. Accessed 2014 